OPEN ACCESS

Edited by:

Anna Milena Zivian,

Ocean Conservancy, United States

Reviewed by:

Martina Hanneliese Stiasny, University of Southampton,

United Kingdom

William Gerald Ambrose Jr.,

Coastal Carolina University, United States

*Correspondence: Hannah L. Green hgr@pml.ac.uk

Specialty section:

This article was submitted to Global Change and the Future Ocean, a section of the journal Frontiers in Marine Science

Received: 30 November 2020 Accepted: 18 May 2021

Published: 16 June 2021

Citation: Green HL, Findlay HS, Shutler JD, Land PE and Bellerby RGJ (2021) Satellite Observations Are Needed to Understand Ocean Acidification and Multi-Stressor Impacts on Fish Stocks in a Changing Arctic Ocean. Front. Mar. Sci. 8:635797. doi: 10.3389/fmars.2021.635797

\section{Satellite Observations Are Needed to Understand Ocean Acidification and Multi-Stressor Impacts on Fish Stocks in a Changing Arctic Ocean}

\author{
Hannah L. Green ${ }^{1,2 *}$, Helen S. Findlay ${ }^{1}$, Jamie D. Shutler ${ }^{2}$, Peter E. Land ${ }^{1}$ and \\ Richard G. J. Bellerby 3,4 \\ ${ }^{1}$ Plymouth Marine Laboratory, Plymouth, United Kingdom, ${ }^{2}$ Centre for Geography, Environment and Society, College of Life \\ and Environmental Sciences, University of Exeter, Penryn, United Kingdom, ${ }^{3}$ Norwegian Institute of Water Research, \\ Bergen, Norway, ${ }^{4}$ State Key Laboratory for Estuarine and Coastal Research, East China Normal University, Shanghai, China
}

It is widely projected that under future climate scenarios the economic importance of Arctic Ocean fish stocks will increase. The Arctic Ocean is especially vulnerable to ocean acidification and already experiences low pH levels not projected to occur on a global scale until 2100. This paper outlines how ocean acidification must be considered with other potential stressors to accurately predict movement of fish stocks toward, and within, the Arctic and to inform future fish stock management strategies. First, we review the literature on ocean acidification impacts on fish, next we identify the main obstacles that currently preclude ocean acidification from Arctic fish stock projections. Finally, we provide a roadmap to describe how satellite observations can be used to address these gaps: improve knowledge, inform experimental studies, provide regional assessments of vulnerabilities, and implement appropriate management strategies. This roadmap sets out three inter-linked research priorities: (1) Establish organisms and ecosystem physiochemical baselines by increasing the coverage of Arctic physicochemical observations in both space and time; (2) Understand the variability of all stressors in space and time; (3) Map life histories and fish stocks against satellite-derived observations of stressors.

Keywords: fish stocks, Arctic Ocean, satellite earth observation, multi-stressor, ocean acidification

\section{INTRODUCTION}

Models project that anthropogenic warming will increase the importance of the Arctic Ocean for supporting economically valuable fish stocks as marine species exploit new ranges and move northwards to remain in their thermal niches or as stock sizes increase (Lam et al., 2014; Cheung et al., 2015; Wisz et al., 2015). Populations of Atlantic cod and haddock, both of significant commercial value, have already expanded their range northwards (Renaud et al., 2012; Fossheim et al., 2015; Misund et al., 2016). Pacific Cod have also been seen to have a summer northward range shift (Spies et al., 2020). However, the Arctic Ocean is particularly susceptible to Ocean acidification (OA), and it is currently unknown how OA will manifest on these northward moving populations. $\mathrm{OA}$ is the change in ocean carbonate chemistry that occurs by the absorption of excess 
carbon dioxide $\left(\mathrm{CO}_{2}\right)$ into the ocean (Doney et al., 2009). Each year the ocean absorbs upwards of $25 \%$ of the anthropogenic $\mathrm{CO}_{2}$ emissions (Friedlingstein et al., 2019; Watson et al., 2020), which has resulted in a $30 \%$ increase in hydrogen ion concentration (decrease in $\mathrm{pH}$ ) since the industrial revolution. Recent assessments suggest regions in the Arctic are already seasonally corrosive to aragonite (a key mineral for some shellbuilding species) as a result of OA (IPCC, 2019). Warming further increases the Arctic's susceptibility to OA, with continued loss of multi-year ice increasing the surface area available for $\mathrm{CO}_{2}$ gas exchange (Bates et al., 2006), while lower salinity and total alkalinity reduces the buffering capacity (Woosley and Millero, 2020). However, the remote and often hostile nature of the Arctic Ocean means collecting in situ data can be costly and challenging; this results in most data sets having a high seasonal bias toward the summer with little data collected under or around multiyear sea ice and/or during winter (Steiner et al., 2014).

The Intergovernmental Panel on Climate Change Special Report on the Ocean and Cryosphere in a Changing Climate acknowledged OA as a risk to shellfish fisheries but overlooked any risk to fin fisheries (IPCC, 2019). Whilst there is debate about the impact of OA on finfish (Kroeker et al., 2013; Haug et al., 2017), there is reasonable evidence from laboratory studies to suggest enough cause for concern (Frommel et al., 2012; Stiasny et al., 2016, 2018, 2019; Dahlke et al., 2017; Supplementary Table 1) and that the changing carbonate chemistry needs to be considered when assessing future fish stocks (Voss et al., 2019). Atlantic cod is the highest landed and most economically valued wild captured species in the Arctic (Pauly et al., 2020) and recent work predicts that although near-future conditions will at first be advantageous to the Atlantic cod (Gadus morchua) fishery in the Northeast Arctic due to reaching the optimal temperature for the spawning stock, once that optimal temperature is reached, further temperature rise combined with OA will lead to a steep decline in stock levels, and by year 2100 the fishery will be at risk of collapse (Hänsel et al., 2020).

Here our aim is to identify the current level of knowledge of the impact of OA combined with other climate change stressors on the most commercially important species in the Arctic. We do this by conducting a literature review, the results of which are primarily single species laboratory studies investigating the impact of OA and other combined stressors. These laboratory studies have their own limitations, and there are still large uncertainties regarding how to scale-up from a single species to ecosystem level (Hänsel et al., 2020). Here we discuss the major knowledge gaps, including some of the caveats of laboratory studies, before putting forward a roadmap of how to close those gaps using satellite observations as an additional tool.

\section{ASSESSING KNOWLEDGE AND GAPS OF IMPACTS OF OA AND MULTIPLE STRESSORS ON FISH STOCKS}

In order to conduct a literature search and assess the current knowledge, the most recently published annual dataset of finfish and shellfish landings in the Arctic Ocean was accessed: the year 2014 data from the "Sea Around Us" database (Pauly et al., 2020). The data was categorized into five biogeochemical regions based on previous work by Carmack and Wassmann (2006) and following Findlay et al. (2015): the Atlantic influenced seas (AiS) and Pacific influenced seas (PiS); the river influenced seas (RiS); the central Arctic Ocean (CAO); and the outflow shelves (OFS) (Figure 1). Further definition of these regions can be found in Supplementary Table 2. Forty-seven species were used in the literature search on OA and multiple stressors impacts. Details of the literature search are in Supplementary Information (section 1.0).

\section{Knowledge Gap 1: Lack of Studies on OA Impacts on Fish, and Their Supporting Food Webs}

The review identified that only ten of the top forty-seven landed species (by tonnage) in the Arctic have been studied for OA impacts, and not all these studies were performed on Arctic populations (Supplementary Table 1 and Figure 1B). Therefore, 37 species remain untested. Responses were found to vary with species and life stage (Figure 1B), though eight of the ten species studied showed a negative response to $\mathrm{OA}$ in one or several of their life stages, particularly larvae and juveniles (Dupont et al., 2014; Dahlke et al., 2017).

Atlantic cod is the most well studied species, with 18 studies identified, results show a complex response to OA (Supplementary Table 1) with many unknowns: e.g., some studies show insignificant (Frommel et al., 2013) and significant (Dahlke et al., 2017) affects from OA on hatching, survival and development of Atlantic cod in the Baltic Sea, the processes behind these different responses are not yet known but it could be that different populations have local adaptations. The evidence for this is not clear, for example populations from the Barents Sea and Western Baltic Sea were both found to have their daily mortality rate approximately double under OA treatment, thus both populations showed similar responses to OA conditions (Stiasny et al., 2016). In other studies, complex responses were found. For example, Mittermayer et al. (2019) found a limited cellular response to $\mathrm{OA}$ in larvae yet at the same stage post hatch larvae were also found to have high mortality. The authors suggested that not enough is known about the mechanism that produces a response to OA in Atlantic Cod. Several studies have found responses to OA that are much more difficult to quantify in terms of ecological consequences such as changes in swimming turn angle and reduced stop duration (Maneja et al., 2013). It is clear further investigation into the mechanisms behind these response to OA is still needed.

Some species, including the Atlantic Cod (Stiasny et al., 2019), Atlantic Herring (Sswat et al., 2018), and Norway lobster (Wood et al., 2015) have shown greater tolerance to OA stress when food is plentiful, highlighting that a change in food supply is likely to have interactive effects with other stressors like OA. The food web perspective must be considered. Indeed, these links between stressors are complex: Sswat et al. (2018), for example, used an ecosystem perspective approach and found that increased primary production from 

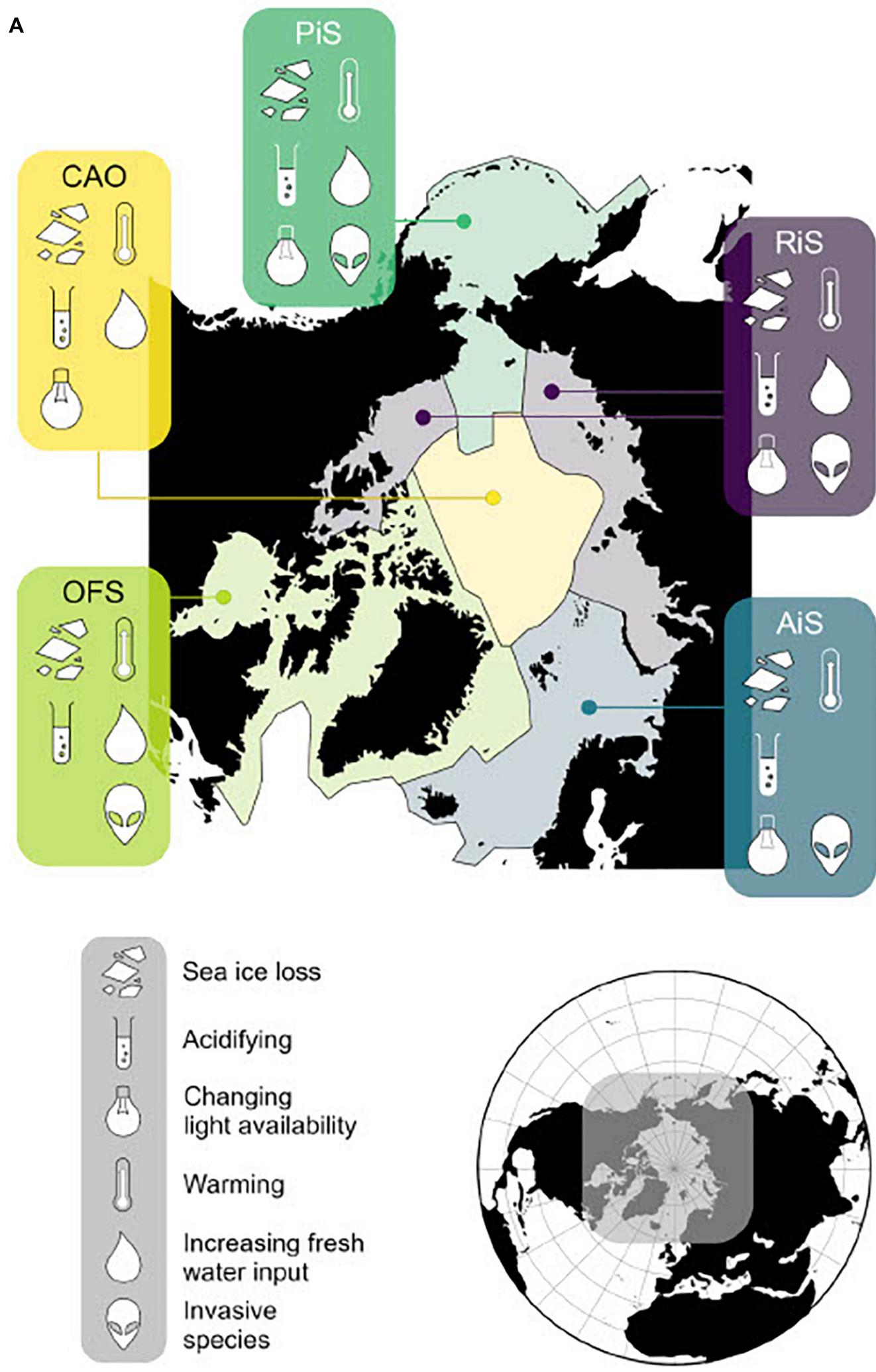


\section{B}
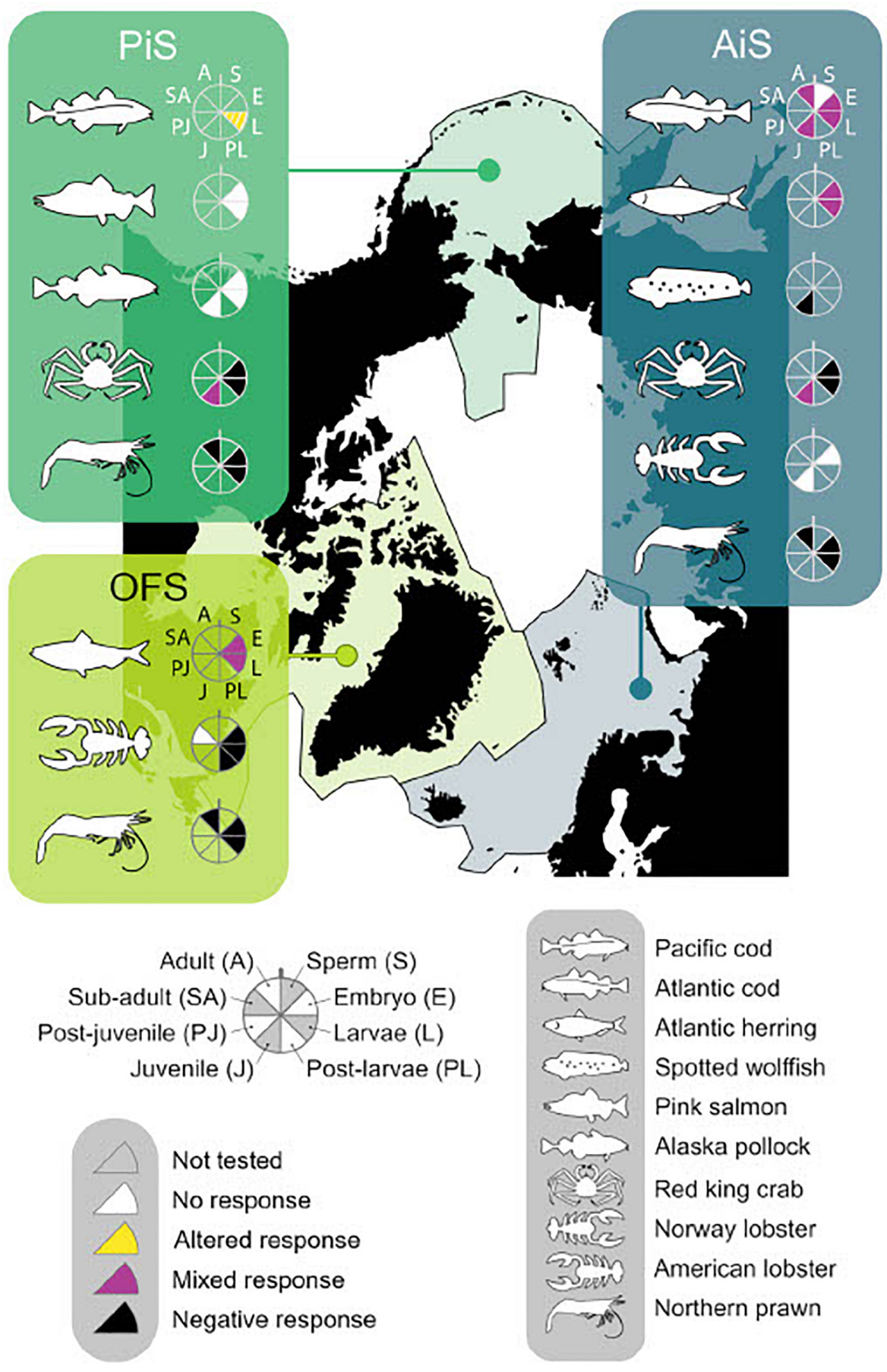

Pacific cod

Atlantic cod

Atlantic herring

Spotted wolffish

Pink salmon

Alaska pollock

Red king crab

Norway lobster

American lobster

Northern prawn

FIGURE 1 | (A) Arctic regional map showing different stressors for each region. AiS, Atlantic influenced seas; PiS, Pacific influenced seas; RiS, river influenced seas; CAO, central Arctic Ocean; OFS, outflow shelves (more detail refer to Supplementary Table 4). (B) Species icons represent each commercial species where response $\mathrm{OA}$ has been studied. Black $=$ negative response, white $=$ no response, blank $=$ not tested, yellow $=$ significantly altered response, purple $=$ mixed response (this includes both positive, negative and significant altered response for more detail refer to Supplementary Table 1). Each life stage tested is represented by the slice of the wheel next to icon of species.

OA increased the survival of Atlantic herring larvae by $19 \%$. This connection between increased primary productivity and alleviation of $\mathrm{OA}$ is particularly interesting in the context of the Arctic as the net primary production of the Arctic
Ocean estimtated to have increased by $30 \%$ from 1998 to 2012 (Arrigo and van Dijken, 2015). However, primary production is also predicted to be limited by stratification, which itself is predicted to increase with ice reduction and 
higher temperatures (Slagstad et al., 2015). It is still unknown if other commercially important species will show the same alleviation from $\mathrm{OA}$ when there is more food available, and further work must be carried out to include this food web perspective.

\section{Knowledge Gap 2: Lack of Understanding of Multiple Stressors}

Understanding climate change interactions on a pan-Arctic scale is difficult as changes are not happening uniformly throughout the Arctic due to regional heterogeneity (Supplementary Table 3 and Figure 1A). The river influenced seas, for example, experience a $\mathrm{pH}$ range of 7.6-8.3 (total scale) and salinity range of 0-34.4, compared to the Atlantic influenced seas, which have a $\mathrm{pH}$ range of 8.1-8.3 and salinity range of 13.6-35.4. Furthermore, tolerance capacity of organisms to OA has been shown to differ with additional stressors (Wood et al., 2015; Harrington and Hamlin, 2019; Stiasny et al., 2019). Organisms in the Arctic Ocean are experiencing changes in multiple oceanic conditions, including salinity, light, (Nicolaus et al., 2012; Langbehn and Varpe, 2017) and food or nutrient supply, predominantly arising from the impacts of sea ice loss (Barber et al., 2015; Polyakov et al., 2017; Dai et al., 2019) and increased river run-off (Peterson et al., 2002; Carmack et al., 2016; Woosley and Millero, 2020: Supplementary Table 4). The changes in salinity, light and food supply can act as stressors impacting on organism tolerance and sensitivity (Jørgensen et al., 2019; Figure 1). Indeed, only nineteen of the OA impact studies found in the literature search had been combined with another stressor (Supplementary Table 1). The main additional stressor tested was temperature, but food was also used as a secondary stressor in several of the studies. It is not yet understood the interactions of multiple climate change factors on organisms more generally, and how this might impact the food web, and therefore indirectly impact fish stocks (Faalenberyg et al., 2018). Only one study was found to have considered any stressors other than temperature and food in conjunction with OA: Hernroth et al. (2015) investigated the impacts of hypoxia and metal contaminant alongside OA. To the best of our knowledge, there are no studies on Arctic-relevant fish species that combine OA with changing light and/or salinity. It is therefore not yet possible to understand the impact of OA combined with additional climate change stressors on present and future Arctic fish stocks.

\section{Knowledge Gap 3: What Environmental Conditions do Arctic Organisms Experience}

Regional heterogeneity and natural variability have largely been neglected from experimental studies, and the Arctic is no exception. The literature review highlights that experimental OA impact studies used $\mathrm{pH}$ levels in their "control" treatments ranging from 8.08 to 7.97 (Supplementary Table 1), with most studies being toward the top end of that range. Given that in situ data shows that organisms in the Arctic may already periodically experience $\mathrm{pH}_{\mathrm{T}}$ as low as 7.6 (Supplementary Table 3), it seems unlikely that these experimental levels reflect true ambient conditions. Furthermore, the Arctic Ocean has large seasonal variability and organisms are unlikely to experience the stable $\mathrm{pH}, \mathrm{pCO}_{2}$, salinity, oxygen and temperature conditions usually used in laboratory experiments (Supplementary Table 1) and are likely to experience different conditions at different life development stages. Seasonal variability can be as much as $\sim 30$ pss salinity, $>10^{\circ} \mathrm{C}$ temperature, $>200 \mu \mathrm{mol} \mathrm{kg}-1$ oxygen (Supplementary Table 3). Indeed, some of the RiS already experience oxygen concentrations at or below $200 \mu \mathrm{mol} \mathrm{kg}{ }^{-1}$. Therefore, the lack of environmental specific treatment levels in experimental studies could be producing misleading results. It is not yet known if Arctic organisms may be pre-conditioned to high levels of $\mathrm{pH}$ variability and exposure to low $\mathrm{pH}$ and may consequently have some tolerance to long-term OA or have some level of adaptation (e.g., Vargas et al., 2017). The studies reviewed here were largely single generation, except for Stiasny et al. (2018) who exposed parents to OA conditions 6 weeks before spawning and found some evidence of transgenerational alleviation in Atlantic Cod when food was plentiful.

\section{THE PATH AHEAD}

Here we present a framework using satellite earth observation to address several of these key knowledge gaps and challenges to determine how present-day conditions and future projected changes will impact Arctic fish stocks. This approach has three inter-linked research aims: (1) Establish organisms and ecosystem physiochemical baselines by increasing the coverage of Arctic physicochemical observations in both space and time; (2) Understand the degree of variability of all stressors in space and time; (3) Map life histories and fish stocks against satellite observation data of stressors. In each of these sub-sections we discuss what is currently feasible with the present knowledge and technology and what additional developments are needed to achieve these aims.

\section{Establish Baselines}

The oceanographic and geographic characteristics of each region in the Arctic Ocean affect how each oceanic region is currently responding to climate change pressures and how they will respond in the future. Automated measurements from satellite observation underpinned by remotely operated vehicles, autonomous vehicles, and buoys (such as data collected from the International Arctic Buoy Programme) offers the only currently available solution to providing the necessary synoptic measurements of multiple oceanographic parameters to characterize surface environmental heterogeneity (Shutler et al., 2019). Satellite observation can be used to study environmental conditions important in polar waters (Shutler et al., 2019) including: freshwater fluxes (e.g., Nichols and Subrahmanyam, 2019); surface water temperature (e.g., Vincent, 2019); Chlorophyll-a concentration, primary production and net community production (e.g., Babin et al., 2015), and sea ice type and depth (e.g., Kwok, 2018). Recent developments have shown that satellite observation measurements of temperature and salinity can provide observational-based estimates of 
surface carbonate system conditions (Land et al., 2019). Although satellite measurements have additional challenges in the Arctic such as land and sea ice contaminations and radio frequency interference, there are now Arctic specific satellite reprocessed datasets to reduce biases (Olmedo et al., 2018). Ongoing development of algorithm work, together with improvement in uncertainties, could provide the ability to remotely observe and characterize multi-year Arctic-wide surface carbonate chemistry and its heterogeneity, and to identify longer-term variations in surface conditions. Therefore, satellite observation data has the potential to fill the gaps in the knowledge required to understand how $\mathrm{OA}$ combined with other climate change factors might affect fish stocks in the Arctic.

\section{Understand and Monitor Temporal Variability and Exposure}

Using satellite observation as a synoptic monitoring tool could provide additional data that can capture the variability on both a pan-Arctic and regional scale. Understanding the degree of variability in carbonate chemistry and other climate change stressors (Figure 1A) in space and time will be vital for improving model predictions. In addition, this will also provide the data for laboratory studies to be more representative of the environmental conditions organisms naturally experience, as well as providing data on a temporal scale for informing studies on multiple generations. This information is also valuable for the biological monitoring community, for understanding how changes in biological communities or processes are related to environmental change. Specifically here, monitoring the longer-term trends together with the variability in carbonate chemistry and other climate change stressors is relevant for understanding which regions are changing fastest and therefore which regions may need fishing and stock management strategies to be implemented.

\section{Map Vulnerabilities}

An aim for future research should be for satellite observation products to be used together with biological datasets to assess what environmental conditions species are experiencing during different life cycle stages. This is important, as many species spend time in different regions, including refugia, depending on their life stage. Mapping the physicochemical conditions alongside biological distribution data allows the identification of species or populations that presently live in more variable environments. This knowledge could be used to test the hypothesis that organisms already exposed to higher variability may have higher tolerance to future environmental change (Vargas et al., 2017). Mapping stressors for a specific organism, ecosystem or region can provide relatively quick assessments of the key stressors, as well as extreme events, which may combine to increase the risk to species and ecosystems. While these mapping activities are potentially very valuable for management and planning, the biological datasets required to do this style of mapping currently do not exist for all regions, species, and life stage. A pan-Arctic scale collaboration for monitoring and mapping, such as an extension to projects like the Arctic Marine Biodiversity Monitoring Network or through the Arctic Council working groups (e.g., Conservation of Arctic Flora and Fauna), would be needed to fill these knowledge gaps.

\section{SOCIETAL RELEVANCE}

Integrated ocean management has been identified as the future methodology to achieving sustainable and resilient marine ecosystems by managing the progress of economic development whilst minimizing environmental impact (Winther et al., 2020). The research priorities proposed here would strengthen the data system needed for ocean policy and progress in governance of marine areas. There are two reasons why now is a crucial time for these ideas to be actioned: (1) the Arctic nation states signed the "Agreement to prevent unregulated high seas fisheries in the Central Arctic ocean" in 2018, providing an opportunity for information and knowledge to be collated before fishing grounds made newly available by ice loss are exploited; and (2) the United Nations Decade of Ocean Science for Sustainable Development from 2021 to 2030 aims to bring together scientists, policy makers, managers, and service users to ensure that ocean science delivers greater benefits for both the ocean ecosystem and society. The regional diversity of the Arctic Ocean does not fit any political boundaries, and adaptation strategies based on an Arctic wide collaboration are more likely to be successful than those based on individual country management. The United Nations Ocean Decade of Ocean Science for Sustainable Development provides an unrivaled opportunity for collaboration, action, and progress among Arctic countries toward ensuring sustainable and healthy fish stocks. Retrieving surface carbonate chemistry data derived from satellite products, together with other, more readily available satellite products provides a wholistic tool for helping to fill the knowledge gaps on the spatial and temporal scales necessary for end-user stakeholders. To implement climate-smart management and adaptation practices, including, for example, establishing marine protected areas, no-take zones, or catchlimits, OA needs to be taken into consideration alongside the other climate stressors.

\section{CONCLUSION AND RECOMMENDATIONS}

Here we highlighted three key points that the current literature is lacking: (1) studies on Arctic fish species; (2) understanding of the impact of multiple stressors; and (3) environmental data on appropriate temporal and spatial resolution to understand what environmental conditions species already experience. We propose that satellite and remotely sensed data can play a key role in filling these gaps as new technologies and developments take shape. To that end we propose a series of recommendations for moving these technologies forward alongside field, laboratory, and modeling research. 
- Use Arctic specific satellite reprocessed datasets to develop Arctic-specific algorithms to monitor carbonate chemistry

- Produce synoptic scale datasets for carbonate chemistry, alongside temperature, ice cover, and ocean color products from satellites, to provide a multi-stressor view

- Improve biological observations of key fish species

- Encourage research into all stages of the life cycle of key fish species

- Continue to develop real-life variability and multistressors into experiments.

\section{AUTHOR CONTRIBUTIONS}

HG conducted the literature search, performed the analysis, and wrote the manuscript. HG, HF, JS, PL, and RB guided the work and contributed to writing. All authors contributed to the article and approved the submitted version.

\section{REFERENCES}

Arrigo, K. R., and van Dijken, G. L. (2015). Continued increases in Arctic Ocean primary production. Prog. Oceanogr. 136, 60-70. doi: 10.1016/j.pocean.2015.05. 002

Babin, M., Bélanger, S., Ellingsen, I., Forest, A., Le Fouest, V., Lacour, T., et al. (2015). Estimation of primary production in the Arctic Ocean using ocean colour remote sensing and coupled physical-biological models: strengths, limitations and how they compare. Prog. Oceanogr. 139, 197-220. doi: 10.1016/ j.pocean.2015.08.008

Barber, D. G., Hop, H., Mundy, C. J., Else, B., Dmitrenko, I. A., Tremblay, J. E., et al. (2015). Selected physical, biological and biogeochemical implications of a rapidly changing Arctic Marginal Ice Zone. Prog. Oceanogr. 139, 122-150. doi: $10.1016 /$ j.pocean. 2015.09 .003

Bates, N. R., Moran, S. B., Hansell, D. A., and Mathis, J. T. (2006). An increasing $\mathrm{CO}_{2}$ sink in the Arctic Ocean due to sea-ice loss. Geophys. Res. Lett. 33:L23609. doi: 10.1029/2006GL027028

Carmack, E., and Wassmann, P. (2006). Food webs and physical-biological coupling on pan-Arctic shelves: unifying concepts and comprehensive perspectives. Prog. Oceanogr. 71, 446-477. doi: 10.1016/j.pocean.2006.10.004

Carmack, E. C., Yamamoto-Kawai, M., Haine, T. W. N., Bacon, S., Bluhm, B. A., Lique, C., et al. (2016). Freshwater and its role in the Arctic Marine System: sources, disposition, storage, export, and physical and biogeochemical consequences in the Arctic and global oceans. J. Geophys. Res. G Biogeosci. 121, 675-717. doi: 10.1002/2015JG003140

Cheung, W. W. L., Brodeur, R. D., Okey, T. A., and Pauly, D. (2015). Projecting future changes in distributions of pelagic fish species of Northeast Pacific shelf seas. Prog. Oceanogr. 130, 19-31. doi: 10.1016/j.pocean.2014.09.003

Dahlke, F. T., Leo, E., Mark, F. C., Pörtner, H. O., Bickmeyer, U., Frickenhaus, S., et al. (2017). Effects of ocean acidification increase embryonic sensitivity to thermal extremes in Atlantic cod, Gadus morhua. Glob. Chang. Biol. 23, 1499-1510. doi: 10.1111/gcb.13527

Dai, A., Luo, D., Song, M., and Liu, J. (2019). Arctic amplification is caused by seaice loss under increasing CO2. Nat. Commun. 10:121. doi: 10.1038/s41467-01807954-9

Doney, S. C., Fabry, V. J., Feely, R. A., and Kleypas, J. A. (2009). Ocean Acidification: the Other CO2 Problem. Annu. Rev. Mar. Sci. 1, 169-192. doi: 10.1146/annurev.marine.010908.163834

Dupont, S., Hall, E., Calosi, P., and Lundve, B. (2014). First evidence of altered sensory quality in a shellfish exposed to decreased $\mathrm{pH}$ relevant to ocean acidification. J. Shellfish Res. 33, 857-861. doi: 10.2983/035.033.0320

Faalenberyg, L. J., Jelmert, A., Mark, F. C., Rost, B., Schulz, K. G., and Thor, P. (2018). Arctic Monitoring and Assessment Programme: biological responses to

\section{FUNDING}

This work was part of a Ph.D. studentship funded by an AXA XL Ocean Risk Scholarship to HG. JS, PL, and HF received partial support by the European Space Agency (ESA) Satellite oceanographic datasets for acidification (OceanSODA) project (contract no. 4000112091/14/I-LG).

\section{ACKNOWLEDGMENTS}

We thank Emma Wood for creating Figure 1.

\section{SUPPLEMENTARY MATERIAL}

The Supplementary Material for this article can be found online at: https://www.frontiersin.org/articles/10.3389/fmars. 2021.635797/full\#supplementary-material

ocean acidification. Technol. Forecast. Soc. Change 89, 201-221. doi: 10.1016/j. techfore.2013.08.036

Findlay, H. S., Gibson, G., Kędra, M., Morata, N., Pavlov, A. K., Reigstad, M., et al. (2015). Responses in Arctic marine carbon cycle processes: conceptual scenarios and implications for ecosystem function. Polar Res. 34:24252. doi: 10.3402/polar.v34.24252

Fossheim, M., Primicerio, R., Johannesen, E., Ingvaldsen, R. B., Aschan, M. M., and Dolgov, A. V. (2015). Recent warming leads to a rapid borealization of fish communities in the Arctic. Nat. Clim. Chang. 5, 673-677. doi: 10.1038/ nclimate 2647

Friedlingstein, P., Jones, M. W., O’Sullivan, M., Andrew, R. M., Hauck, J., Peters, G. P., et al. (2019). Global Carbon Budget 2019. Earth Syst. Sci. Data 11, 1783-1838. doi: 10.3929/ethz-b-000385668

Frommel, A. Y., Maneja, R., Lowe, D., Malzahn, A. M., Geffen, A. J., Folkvord, A., et al. (2012). Severe tissue damage in Atlantic cod larvae under increasing ocean acidification. Nat. Clim. Chang. 2, 42-46. doi: 10.1038/nclimate 1324

Frommel, A. Y., Schubert, A., Piatkowski, U., and Clemmesen, C. (2013). Egg and early larval stages of Baltic cod, Gadus morhua, are robust to high levels of ocean acidification. Mar. Biol. 160, 1825-1834. doi: 10.1007/s00227-011-1876-3

Hänsel, M. C., Schmidt, J. O., Stiasny, M. H., Stöven, M. T., Voss, R., and Quaas, M. F. (2020). Ocean warming and acidification may drag down the commercial Arctic cod fishery by 2100. PLoS One 15:e0231589. doi: 10.1371/journal.pone. 0231589

Harrington, A. M., and Hamlin, H. J. (2019). Ocean acidification alters thermal cardiac performance, hemocyte abundance, and hemolymph chemistry in subadult American lobsters Homarus americanus H. Milne Edwards, 1837 (Decapoda: Malcostraca: Nephropidae). J. Crustac. Biol. 39, 468-476. doi: 10. 1093/jcbiol/ruz015

Haug, T., Bogstad, B., Chierici, M., Gjøsaeter, H., Hallfredsson, E. H., Høines, Å. S., et al. (2017). Future harvest of living resources in the Arctic Ocean north of the Nordic and Barents Seas: a review of possibilities and constraints. Fish. Res. 188, 38-57. doi: 10.1016/j.fishres.2016.12.002

Hernroth, B., Krång, A. S., and Baden, S. (2015). Bacteriostatic suppression in Norway lobster (Nephrops norvegicus) exposed to manganese or hypoxia under pressure of ocean acidification. Aquat. Toxicol. 159, 217-224. doi: 10.1016/j. aquatox.2014.11.025

IPCC (2019). IPCC Special Report on the Ocean and Cryosphere in a Changing Climate. Available online at: https://www.ipcc.ch/srocc/ (accessed September 30, 2019)

Jørgensen, L. L., Primicerio, R., Ingvaldsen, R. B., Fossheim, M., Strelkova, N., Thangstad, T. H., et al. (2019). Impact of multiple stressors on sea bed fauna in a warming Arctic. Mar. Ecol. Prog. Ser. 608, 1-12. doi: 10.3354/meps12803 
Kroeker, K. J., Kordas, R. L., Crim, R., Hendriks, I. E., Ramajo, L., Singh, G. S., et al. (2013). Impacts of ocean acidification on marine organisms: quantifying sensitivities and interaction with warming. Glob. Chang. Biol. 19, 1884-1896. doi: $10.1111 /$ gcb.12179

Kwok, R. (2018). Arctic sea ice thickness, volume, and multiyear ice coverage: Losses and coupled variability (1958-2018). Environ. Res. Lett. 13:105005. doi: 10.1088/1748-9326/aae3ec

Lam, V. W. Y., Cheung, W. W. L., and Sumaila, U. R. (2014). Marine capture fisheries in the Arctic: winners or losers under climate change and ocean acidification? Fish Fish. 17, 335-357. doi: 10.1111/faf. 12106

Land, P. E., Findlay, H. S., Shutler, J. D., Ashton, I. G. C., Holding, T., Grouazel, A., et al. (2019). Remote Sensing of Environment Optimum satellite remote sensing of the marine carbonate system using empirical algorithms in the global ocean, the Greater Caribbean, the Amazon Plume and the Bay of Bengal. Remote Sens. Environ. 235:111469. doi: 10.1016/j.rse.2019.111469

Langbehn, T. J., and Varpe, Ø. (2017). Sea-ice loss boosts visual search: fish foraging and changing pelagic interactions in polar oceans. Glob. Chang. Biol. 23, 5318-5330. doi: 10.1111/gcb.13797

Maneja, R. H., Frommel, A. Y., Browman, H. I., Clemmesen, C., Geffen, A. J., Folkvord, A., et al. (2013). The swimming kinematics of larval Atlantic cod, Gadus morhua L., are resilient to elevated seawater $\mathrm{pCO}_{2}$. Mar. Biol. 160, 1963-1972. doi: 10.1007/s00227-012-2054-y

Misund, O. A., Heggland, K., Skogseth, R., Falck, E., Gjøsaeter, H., Sundet, J., et al. (2016). Norwegian fisheries in the Svalbard zone since 1980. Regulations, profitability and warming waters affect landings. Polar Sci. 10, 312-322. doi: 10.1016/j.polar.2016.02.001

Mittermayer, F. H., Stiasny, M. H., Clemmesen, C., Bayer, T., Puvanendran, V., Chierici, M., et al. (2019). Transcriptome profiling reveals exposure to predicted end-of-century ocean acidification as a stealth stressor for Atlantic cod larvae. Sci. Rep. 9:16908. doi: 10.1038/s41598-019-52628-1

Nichols, R. E., and Subrahmanyam, B. (2019). Estimation of Surface Freshwater Fluxes in the Arctic Ocean Using Satellite-Derived Salinity. Remote Sens. Earth Syst. Sci. 2, 247-259. doi: 10.1007/s41976-019-00027-5

Nicolaus, M., Katlein, C., Maslanik, J., and Hendricks, S. (2012). Changes in Arctic sea ice result in increasing light transmittance and absorption. Geophys. Res. Lett. 39:L24501. doi: 10.1029/2012GL053738

Olmedo, E., Gabarró, C., González-Gambau, V., Martínez, J., Ballabrera-Poy, J., Turiel, A., et al. (2018). Seven Years of SMOS sea surface salinity at high latitudes: variability in Arctic and Sub-Arctic Regions. Remote Sens. 10, 1-24. doi: $10.3390 /$ rs 10111772

Pauly, D., Zeller, D., and Palomares, M. L. D. (2020). Sea Around Us Concepts, Design and Data. Available online at: seaaroundus.org (accessed April 30, 2020)

Peterson, B. J., Holmes, R. M., McClelland, J. W., Vörösmarty, C. J., Lammers, R. B., Shiklomanov, A. I., et al. (2002). Increasing river discharge to the Arctic Ocean. Science 298, 2171-2173. doi: 10.1126/science.1077445

Polyakov, I. V., Pnyushkov, A. V., Alkire, M. B., Ashik, I. M., Baumann, T. M., Carmack, E. C., et al. (2017). Greater role for Atlantic inflows on sea-ice loss in the Eurasian Basin of the Arctic Ocean. Science 356, 285-291. doi: 10.1126/ science.aai8204

Renaud, P. E., Berge, J., Varpe, O., Lønne, O. J., Nahrgang, J., Ottesen, C., et al. (2012). Is the poleward expansion by Atlantic cod and haddock threatening native polar cod, Boreogadus saida? Polar Biol. 35, 401-412. doi: 10.1007/ s00300-011-1085-z

Shutler, J. D., Wanninkhof, R., Nightingale, P. D., Woolf, D. K., Bakker, D. C. E., Watson, A., et al. (2019). Satellites will address critical science priorities for quantifying ocean carbon. Front. Ecol. Environ. 10:2129. doi: 10.1002/fee.2129

Slagstad, D., Wassmann, P. F. J., and Ellingsen, I. (2015). Physical constrains and productivity in the future Arctic Ocean. Front. Mar. Sci. 2:85. doi: 10.3389/ fmars.2015.00085

Spies, I., Gruenthal, K. M., Drinan, D. P., Hollowed, A. B., Stevenson, D. E., Tarpey, C. M., et al. (2020). Genetic evidence of a northward range expansion in the eastern Bering Sea stock of Pacific cod. Evol. Appl. 13, 362-375. doi: 10.1111/eva.12874

Sswat, M., Stiasny, M. H., Jutfelt, F., Riebesell, U., and Clemmesen, C. (2018). Growth performance and survival of larval Atlantic herring, under the combined effects of elevated temperatures and $\mathrm{CO}_{2}$. PLoS One 13:e191947. doi: 10.1371/journal.pone.0191947

Steiner, N. S., Christian, J. R., Six, K. D., and Yamamoto, A. (2014). Future ocean acidification in the Canada Basin and surrounding Arctic Ocean from CMIP5 earth system models. J. Geophys. Res. Ocean 119, 332-347. doi: 10.1002/ 2013JC009069

Stiasny, M. H., Mittermayer, F. H., Göttler, G., Bridges, C. R., Falk-Petersen, I. B., Puvanendran, V., et al. (2018). Effects of parental acclimation and energy limitation in response to high $\mathrm{CO}_{2}$ exposure in Atlantic cod. Sci. Rep. 8:8348. doi: 10.1038/s41598-018-26711-y

Stiasny, M. H., Mittermayer, F. H., Sswat, M., Voss, R., Jutfelt, F., Chierici, M., et al. (2016). Ocean acidification effects on Atlantic cod larval survival and recruitment to the fished population. PLoS One 11:e0155448. doi: 10.1371/ journal.pone. 0155448

Stiasny, M. H., Sswat, M., Mittermayer, F. H., Falk-Petersen, I. B., Schnell, N. K., Puvanendran, V., et al. (2019). Divergent responses of Atlantic cod to ocean acidification and food limitation. Glob. Chang. Biol. 25, 839-849. doi: 10.1111/ gcb. 14554

Vargas, C. A., Lagos, N. A., Lardies, M. A., Duarte, C., Manríquez, P. H., Aguilera, V. M., et al. (2017). Species-specific responses to ocean acidification should account for local adaptation and adaptive plasticity. Nat. Publ. Gr. 1:0084. doi: 10.1038/s41559-017-0084

Vincent, R. F. (2019). The case for a single channel composite arctic sea surface temperature algorithm. Remote Sens. 11, 1-13. doi: 10.3390/rs1120 2393

Voss, R., Quaas, M. F., Stiasny, M. H., Hänsel, M., Stecher Justiniano Pinto, G. A., Lehmann, A., et al. (2019). Ecological-economic sustainability of the Baltic cod fisheries under ocean warming and acidification. J. Environ. Manage. 238, 110-118. doi: 10.1016/j.jenvman.2019.02.105

Watson, A. J., Schuster, U., Shutler, J. D., Holding, T., Ashton, I. G. C., Landschützer, P., et al. (2020). Revised estimates of ocean-atmosphere $\mathrm{CO}_{2}$ flux are consistent with ocean carbon inventory. Nat. Commun. 11:4422. doi: 10.1038/s41467-020-18203-3

Winther, J. G., Dai, M., Rist, T., Hoel, A. H., Li, Y., Trice, A., et al. (2020). Integrated ocean management for a sustainable ocean economy. Nat. Ecol. Evol. 4, 1451-1458. doi: 10.1038/s41559-020-1259-6

Wisz, M. S., Broennimann, O., Grønkjaer, P., Møller, P. R., Olsen, S. M., Swingedouw, D., et al. (2015). Arctic warming will promote Atlantic-Pacific fish interchange. Nat. Clim. Chang. 5, 261-265. doi: 10.1038/nclimate2500

Wood, H. L., Eriksson, S. P., Nordborg, M., and Styf, H. K. (2015). The effect of environmental stressors on the early development of the Norway lobster Nephrops norvegicus (L.). J. Exp. Mar. Bio. Ecol. 473, 35-42. doi: 10.1016/j. jembe.2015.08.009

Woosley, R. J., and Millero, F. J. (2020). Freshening of the western Arctic negates anthropogenic carbon uptake potential. Limnol. Oceanogr. 65, 1834-1846. doi: $10.1002 / \operatorname{lno} .11421$

Conflict of Interest: The authors declare that the research was conducted in the absence of any commercial or financial relationships that could be construed as a potential conflict of interest.

Copyright (c) 2021 Green, Findlay, Shutler, Land and Bellerby. This is an openaccess article distributed under the terms of the Creative Commons Attribution License (CC BY). The use, distribution or reproduction in other forums is permitted, provided the original author(s) and the copyright owner(s) are credited and that the original publication in this journal is cited, in accordance with accepted academic practice. No use, distribution or reproduction is permitted which does not comply with these terms. 